\title{
Long Course Chemoradiotherapy
}

National Cancer Institute

\section{Source}

National Cancer Institute. Long Course Chemoradiotherapy. NCI Thesaurus. Code

C142874.

Chemoradiotherapy generally consisting of 45 Gy given in 25 fractions over 5 weeks with concomitant chemotherapy as a radiosensitizer. 